\title{
The Study of High-resolution Sequence Stratigraphy of Fuyu Reservoir in Toutai Oilfield
}

\author{
Guangbin $\mathrm{Hu}^{1, \mathrm{a}}$, Jingwei $\mathrm{Li}^{1, \mathrm{c}}$, Dan Zhong ${ }^{2, \mathrm{~b}}$ \\ ${ }^{1}$ Daqing Toutai Oilfield Development Co , Ltd, Daqing City, China \\ ${ }^{2}$ Northeast Petroleum University, Daqing City, China \\ aHthzm189@126.com , ${ }^{\mathrm{b} P d h q s 9116 @ 126 . c o m ~, ' Z h o n g d a n 920114 @ 126 . c o m ~}$
}

\begin{abstract}
Key word: high-resolution sequence stratigraphy; complex sand body; short-term base level cycles; Fu Yu reservoir; Tou Tai oilfield; Mao SHI and SHI YI blocks

Abstract. Due to long-term development of water injection and vague awareness of heterogeneity in Tou Tai oilfield, remaining oil form and gather, which form potential area. In order to resolve this problem, fine division and correlation of strata is needed. In guidance of theory in high-resolution sequence, considering level and using core 、 logging and seismic data, High-resolution sequence stratigraphy has been studied. Study show that $\mathrm{Fu} \mathrm{Yu}$ reservoir can be divided into 3 long-term、 18 mid-term、34 short-term base level cycles. Through the identification of sequence interface in single well and using well logging curve shape - marker bed changes in strata thickness v characteristic in lithological combination to conduct correlation of strata, then chronostratigraphic sequence framework is established. And complex sand body is accurately divided and correlate into single sand body, which provide vitally geologic bases to remaining oil for potential exploration.
\end{abstract}

\section{Introduction}

Tou Tai oilfield is located in Zhaoyuan country, Heilongjjiang Province, Daqing city. In regional tectonic position, it locate in west of Chao Yanggou terrace, central depression area, Songliao Basin, which is a nose-like structure of the north west of pitching. Fu Yu reservoir belongs to Quan third and Quan fourth stratigraphy in lower cretaceous, which is a series of interactive sedimentary sand and mudstone, the average stratigraphic thickness is about $260 \mathrm{~m}$, river-delta sedimentary system is developed. From Tou Tai oil field development, it entered high water bearing now. Due to wobble and incision of channel sand, reservoir has strong heterogeneity in plane and vertical, which limited the development of remaining $\mathrm{oil}^{[1-4]}$. Aiming at the problems existing in the process of development, the high-resolution sequence stratigraphy is established. Fine depiction of single sand body provides vitally geologic bases for changes in method of development and potential development ${ }^{[5-7]}$.

\section{The division of high-resolution sequence stratigraphy}

Firstly, the location of purpose layer can be confirmed by using logging data. Through the observation of characteristic of logging curve in whole area, the top of $\mathrm{Fu} \mathrm{Yu}$ reservoir can be identified. There are there layers of oil shale on the top of Fu Yu reservoir, which have high value in resistivity $\mathrm{AC}$ and GR. The bottom of Fu Yu reservoir is limnetic facies. There is a highest value in $\mathrm{AC}$ and GR, a lowest value in resistivity locally in logging curves. So the location of $\mathrm{Fu} \mathrm{Yu}$ reservoir is confirmed by the maker bed of top and bottom. Because the maker bed of top and bottom develop widely and have isochronism, large-scale isochronous stratigraphic framework is established. On this basis, according to the logging curve shape、core、 lithological association and stratigraphic thickness, the interface of different levels of base level cycle can be identified in key wells, and divide stratigraphy. Then using the skeleton section, the division of key well can be applied to every well in study area, so fine division and correlation in the whole area can be implemented. The purpose of strata study is that strata should be precise into single sand body, which is equivalent to short-term base level cycles. The principle of method of division: (1)The 
interface of single sand body is equivalent to turning point form base level rising cycle to base level declining cycle or form base level declining cycle to base level rising cycle; (2)The thickness of single sand body should surpass the thickness of single channel sand body, so the integrity of permeability of single sand body can guarantee; (3)The thickness of single sand body should have representation, which prevent crossing strata; (4)The bottom interface of single sand body is mainly channel erosional surface. The division of strata should not be much fine, because it enhance the risk of crossing layers. If the division of strata is very rough, it will can't satisfy the need of development, and the heterogeneity of reservoir is obvious. In a word, there is a close integration between the division of stratigraphy and actual demand. This study use common classification system, namely long-term base level cycles, mid-term base level cycles and short-term base level cycles. Through study, Fu Yu reservoir is further divided into F I 、 F II 、 FIII three long-term base level cycles, F I 1-F I 8 、 F II 1-F II 5 、 FIII1-FIII5 eighteen mid-term base level cycles, F I 1a-F I 8b 、 F II 1a-F II 5b 、 FIII1a-FIII5a thirty-four short-term base level cycles, namely thirty-four single sand body(Fig.1).

\section{The correlation of high-resolution sequence stratigraphy}

\subsection{The identification of interface about single well's high-resolution sequence stratigraghy}

The analysis of high-resolution sequence stratigraphy in single well need to identify and divide different levels of base level cycles. There are nearly 400 wells in study area, the turning point of short-term base level cycles is identified by the log curves of resistivity and GR, which is relevant to lake flooding plane and erosional surface in channel. At the same time, referencing the combination feature of different cycles of core well in vertical, the response characteristics of long-term base level cycles、mid-term base level cycles、short-term base level cycles are established in every well. The interface of base level cycle of single well can apply to the whole area by close skeleton section, finally the division and correlation of single layer is finished.

\subsection{The method of correlation}

The correlation of marker bed

Marker bed is a widespread strata which is formed in the same time and sedimentary environment, and has obviously lithological characteristics. Through the observation of the log curves in whole area, there are other two marker bed in the purpose layer except the maker bed in top and bottom, they are the bottom interface of F I 8a and F II 1c, which develop commonly in study area. The characteristics of log curves: high value of resistivity, low value of AC, low value of GR, the characteristic of the two marker beds is familiar, which develop $80 \%$.

The correlation of closed skeleton section

In section, strata is divided and correlated by depending on the changes of curve shape of resistivity、GR、AC and the combination of sedimentary cycles. Firstly, closed skeleton section is established ,it have two direction that respectively parallel the direction of source and is vertical to the direction of source. Key well should be in among closed skeleton section, and bypass the fault, which enhance the accuracy of former correlation of stratigraphy and decline the difficult in correlation from the fault. 


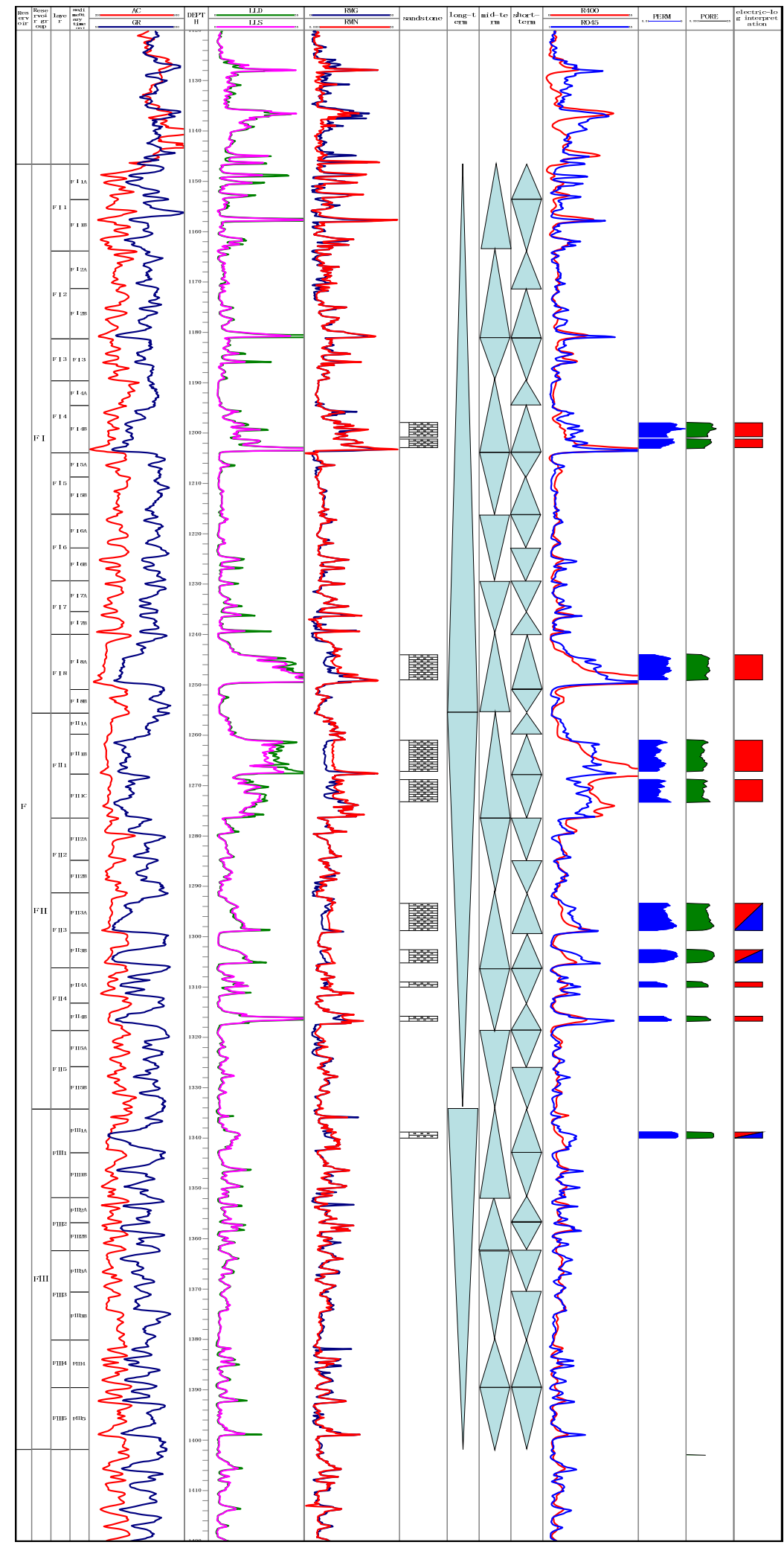

Fig.1 Single-well response model of short-term datum plane cycles of Well M64-91.

\subsection{The analysis about results of correlation}

Through the analysis of high-resolution sequence stratigraphy, the purpose layer is divided into 34 short-term base level cycles. Taking F I 8a、 F II 1b and F II 1c as examples, through the map of thickness of sand in different single sand layer(Fig.2), it's obvious that different single sand layer have different thickness of sand, the distribution of sand present a direction which is along the southwest and northeast. All those fact indicate that the source of purpose layer is from the southwest. At the same time, the contour of sand thickness show the characteristic of separation, which reflect that channel have the feature of forfication and swing. The fact above conform to 
geological law, which demonstrate the special advantage of high-resolution sequence stratigraphy. Because the interface of base level cycles is identified by the turning point of base level cycles, it reflect the principle of isochronous correlation during the process of strata correlation.

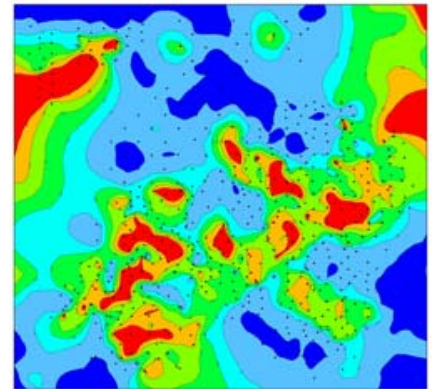

(a)

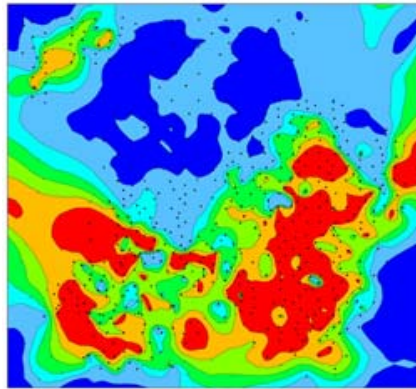

(b)

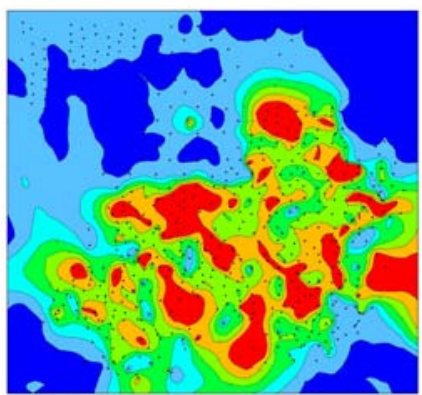

(c)

Fig.2 The contour map of thickness in sand body of F I 8(a)、F II 1b(b)、F II 1c(c)

\section{The identification of single sand body using high-resolution sequence stratigraghy}

In the middle and late development in oil field, large-scale correlation can't satisfy the need in production, so the layer should be divide to single sand body. Oil and gas exist in underground reservoir, single sand body is the basic unit for transfusion of oil and gas ${ }^{[8-9]}$. The true identification of single sand body is the precondition for connection of sand body and analyzing injection-production relation. Through the high-resolution sequence stratigraphy ,the complex sand body can divided into different single sand body in different time, which provides vitally geologic bases for changes in method of development and potential development.

\section{Conclusion}

1、 Though marker bed, the location of purpose layer can be confirmed in well log curves, and large-scale isochronous stratigraphic framework is established, which avoids time-transitional mistakes in division and correlation of stratigraphy.

2、By identification of different ranks base level cycle interface in key well, namely strata is divided by lake flooding surface and erosional surface in the bottom of river. Finally, $\mathrm{Fu} \mathrm{Yu}$ reservoir is divided into 3 long-term base level cycles、 18 mid-term base level cycles 34 short-term base level cycles, namely the division of stratigraphy is precision into a level of single sand body.

3、 On the basis of identification of high-resolution sequence stratigraphy interface characteristics in single well, combination of marker bed and closed skeleton section, high-resolution sequence stratigraphy of a level of single sand body is established. According to the contour map of thickness in main sand body, the source is confirmed southwest direction. At the same time, isochronal stratigraphic framework solve a problem that complex sandbody divided into single sandbody in vertical, which provide a firm basement for fine depiction of single sandbody and the adjustment of production strategy.

\section{Acknowledgement}

The authors would like to show special thanks to Mr. Shizhong Ma for his technical supports on field. This work is funded by National high technology research and development program (2013AA064903)。

\section{References}

[1] Cross T A, Lessenger M A. Sediment volume partitioning: retionale for stratigraphic model evaluation and high-resolution stratigraphic correlation[J]. Sequence Stratigraphy-Concepts and Application. Norwegian Petroleum Society Special Publication,1998,6(8):171-195. 
[2] Deng Hongwen, Wang Hongliang, Ning Ning. Sediment volume partition principle: theory basic for high resolution sequence stratigraphicy[J]. Earth Science Frontiers,2000,7(4):305-313.

[3] Shi Lanting, Pan Shuxin, Guo Weihua, et al. Sequence boundary characteristic and its high-resolution sequence stratigraphic framework of the middle oil bearing beds in the south of Songliao Basin[J]. Acta Sedimentologica Sinica, 2010,28(2):235-242

[4] Tian shicun, Liu Guochen, Tang Lei, et al. Sequence stratigraphic framework and play fairways in Block B of the South Sumatra Basin[J]. Oil \& Gas Geology,2013,34(1):68-76.

[5] Ruan Zhuang, Zhu Xiaomin, He Yuhang, et al. High-resolution sequence stratigraphy division of upper Putaohua reservoir, northern Daqing Placanticline[J]. Acta Sedimentologica Sinica,2012,30(2):301-309.

[6] Liang Hongwei, Wu Shanghe, Yue Dali, et al. Base-level cyclic influenced facies-controlling porosity-permeability log interpretation model: A case study of the fluvial facies in 2 block of the Shengtuo Oilfield[J]. Natural Gas Geoscience,2013,24(3):574-581.

[7] Sun Yu, Ma Shizhong, Zhang Xiuli, et al, High-resolution sequence stratigraphic division and monosandbody isochronic correlation of meandering river delta of Fuyu reservoir in the north of Honggang area[J]. Journal of oil and gas technology,2010,32(1),22-27.

[8] Chen Huanqing, Zhao Yingcheng, Gao Xingjun, et al, High-resolution sequence stratigraphy and its application in the fine-scale stratigraphic correlation of the Yulou reservoir in the west depression of the Liao He Basin[J],journal of stratigraphy,2014,38(3):317-323.

[9] Liu Zongbao, Ma Shizhong, Sun Yu, et al, High-resolution sequence stratigraphy division depositional characteristics of Putaohua reservoir, Sanzhao Depression[J],Acta sedmentologica sinica,2008,26(3),399-406. 